\title{
RELIABILITY ANALYSIS OF THE PZL-130 ORLIK TC-II AIRCRAFT STRUCTURAL COMPONENT UNDER REAL OPERATING CONDITIONS
}

\section{ANALIZA NIEZAWODNOŚCI ELEMENTU STRUKTURY NOŚNEJ SAMOLOTU PZL- 130 ORLIK TC-II W RZECZYWISTYCH WARUNKACH EKSPLOATACJ**}

\begin{abstract}
The theme of the paper is to present development of new methods for assessing the reliability of the aircraft structure. Based on the described mathematical models, the author developed the "Aircraft Structural Reliability Assessment" (AStRAss) computer software, which implements the realized mathematical model. The aim of the software is calculation of aircraft structure reliability. In this contribution the failure rate of the selected location within the structure of the PZL-130 Orlik TC-II under real operating conditions were calculated. For the chosen control point within the structure the sensitivity of failure rate to the input data was investigated.
\end{abstract}

Keywords: airframe, risk analysis, reliability research, single flight probability of failure, PZL-130 Orlik TC-II.

Tematem publikacji jest przedstawienie opracowanej metody oceny niezawodności struktury nośnej statków powietrznych. Wykorzystujac opisane modele matematyczne stworzono autorskie oprogramowanie komputerowe Aircraft Structural Reliability Assessment (AStRAss), implementujące opracowany model w celu obliczenia niezawodności struktury nośnej statków powietrznych. W niniejszej pracy określono chwilowa intensywność uszkodzeń w wybranym miejscu struktury samolotu PZL-130 TC II Orlik dla rzeczywistych warunków eksploatacji. Dla wybranego punktu kontrolnego przedstawiono w pracy również analize wrażliwości wyników na zmiany istotnych parametrów wejściowych.

Stowa kluczowe: struktura nośna samolotu, badania niezawodnościowe, chwilowa intensywność niesprawności, PZL-130 Orlik TC-II.

\section{Introduction}

This article presents a method of reliability prediction as well as sustainability of selected areas of the airframe in the aspect of fatigue and ageing processes. Supporting structure may be classified as an element with strongly correlated changes of airworthiness parameter values with the correct operation time of the aircraft [28].

One of the most important issues associated with aircraft maintenance is durability analysis of their structure components [10,27]. The previous experience in operation confirms that exhaustion of aircraft service life cannot be unambiguously identified with its unserviceability for further, reliable flights. Not always does the service life exhaustion results in losing the aircraft technical efficiency and exceeding the assumed dependability parameters $[6,7]$. The inadequacies of the traditional (service life) approach to aircraft maintenance used were the reason to initiate works in the field of developing new methods for assessing the durability of the aircraft structure, which will be presented in this article [21,23].

The described mathematical model is implemented with the use of specialized software, created by the author of the publication, known as Aircraft Structural Reliability Assessment" (AStRAss). United States Air Force [1, 4], in order to conduct reliability analysis of aircraft structure, uses the Probability Of Fracture (PROF) program [13], whose math kernel was written on the basis of the same equation. National Research Council Canada [12, 25] uses a similar mathematical approach for reliability analysis of aircraft structure in its ProDTA (PRObabilistic Damage Tolerance Analysis) software.

The presented method and the results of operational experience make it possible to extend aircraft service life. Discussed procedures are not performed for aircraft owned by Polish Air Force, particularly for PZL-130 Orlik TC-II aircraft. Such analyses are conducted only by Lockheed Martin, in exploitation of F-16s.

\section{Presentation of the reliability assessment model}

Failure rate function $[2,9]$ is defined as the limit of quotient of conditional probability of failure occurence in time interval $t+\Delta t$, under the condition of lasting out to time interval $t$ by $\Delta t$, when $\Delta t$ leads to zero, which can be described as:

$$
\lambda(t)=\lim _{\Delta t \rightarrow 0^{+}} \frac{P\{t<T \leq t+\Delta t \mid T>t\}}{\Delta t}
$$

where $T$ is a continuous positive random variable of device operation time.

If random variable $T$ has a function of density $f(t)$ as well as cumulative distribution function $F(t)$, the equation (1) will take the form of:

$$
\lambda(t)=\frac{f(t)}{1-F(t)}
$$

where $F(t)=\int_{0}^{t} f(u) d u=P\{T \leq t\}=1-P\{T>t\}$.

Given the failure rate $\lambda(t)$ the life distribution can be calculated by the equation:

(*) Tekst artykułu w polskiej wersji językowej dostępny w elektronicznym wydaniu kwartalnika na stronie www.ein.org.pl 


$$
F(t)=1-e^{-\int^{t} \lambda(x) d x}
$$

In the aircraft reliability analysis to determine the probability of failure two independent events are taken into consideration. The failure can be recognized as a state in which:

- crack length exceeds a pre-defined size $a_{c r}$,

- for a crack size smaller than $a_{c r}$ there will be a stress cycle, which will produce a stress intensity factor $K$ exceeding the fracture toughness $K_{c}$.

Failure rate for a place in aircraft structure is calculated using the equation $[14,22]$ :

$$
\lambda(t)=\lambda_{1}(t)+\lambda_{2}(t)
$$

where: $\lambda_{1}(t)-$ failure rate resulting from exceeding the allowable crack length $a_{c p}$

$\lambda_{2}(t)$ - failure rate resulting from exceeding the allowable stress in flight.

Based on the knowledge of the failure rate $\lambda(t)$ failure function can be calculated using the equation (3) for a single location.

Function $g$ which defines the relation between crack length from the quotient of stress intensity factor by stresses can be expressed as [8]:

$$
K / \sigma=\sqrt{\pi a} \beta(a)=g(a)
$$

where: $\sigma-$ stress,

$\beta(a)$-geometry correction factor specified for a cracks length $a$.

For the material under consideration and a specific location in the aircraft supporting structure, the critical crack size $a_{c r}$ is a value corresponding to a mean value of the fracture toughness $\overline{K_{c}}$ and the modal value of stresses occurring in flights for the place under discussion, which can be mathematically represented as:

$$
a_{c r}=g^{-1}\left(\frac{\overline{K_{c}}}{\tilde{\sigma}}\right)
$$

The probability of component failure during a time period $(0, t)$ caused by exceeding the allowable crack length can be described as:

$$
F_{L c r}(t)=1-F_{A}\left(a^{*}\left(t_{c r}-t\right)\right)
$$

where: $F_{A}$ - the distribution function of the initial crack length, $a^{*}(t)$-function of crack length corresponding to the time to the occurrence of failure $t_{f}=t_{c r}-t$,

$t_{c r}-$ the time, when crack size will reach the predefined value $a_{c r}$

Failure rate associated with exceeding the permissible crack size $a_{c r}$ might be calculated by the following equation (2):

$$
\lambda_{1}(t)=\frac{f_{L c r}(t)}{1-F_{L c r}(t)}
$$

where: $\quad f_{L c r}=\frac{d F_{L c r}}{d t}$.

The probability that the stress value will cause a failure during a flight at time $t$ for cracks smaller than $a_{c r}$ can be calculated with the following equation:

$$
P_{N}(t)=\int_{0}^{\infty} \int_{0}^{a_{c r}} \hat{H}\left(\sigma_{c r}\left(a, k_{c}\right)\right) f_{A}(a) d a \cdot f_{K_{c}}\left(k_{c}\right) d k_{c}
$$

where: $\hat{H}=1-H=P\left\{\sigma>\sigma_{c r}=K_{c} / \beta(a) \sqrt{\pi a}\right\}$ is the exceedance probability for the peak load per flight,

$f_{A}(a)$ is the density of the flaw size distribution at time interval $t$,

$f_{K_{c}}\left(k_{c}\right)$ is the density distribution of fracture toughness,

$P O F(t)$ is the probability that a peak load will cause a failure during a flight at time $t$.

Failure rate due to a large stress can then be approximated by:

where $g^{-1}$ is the inversion of function (5).

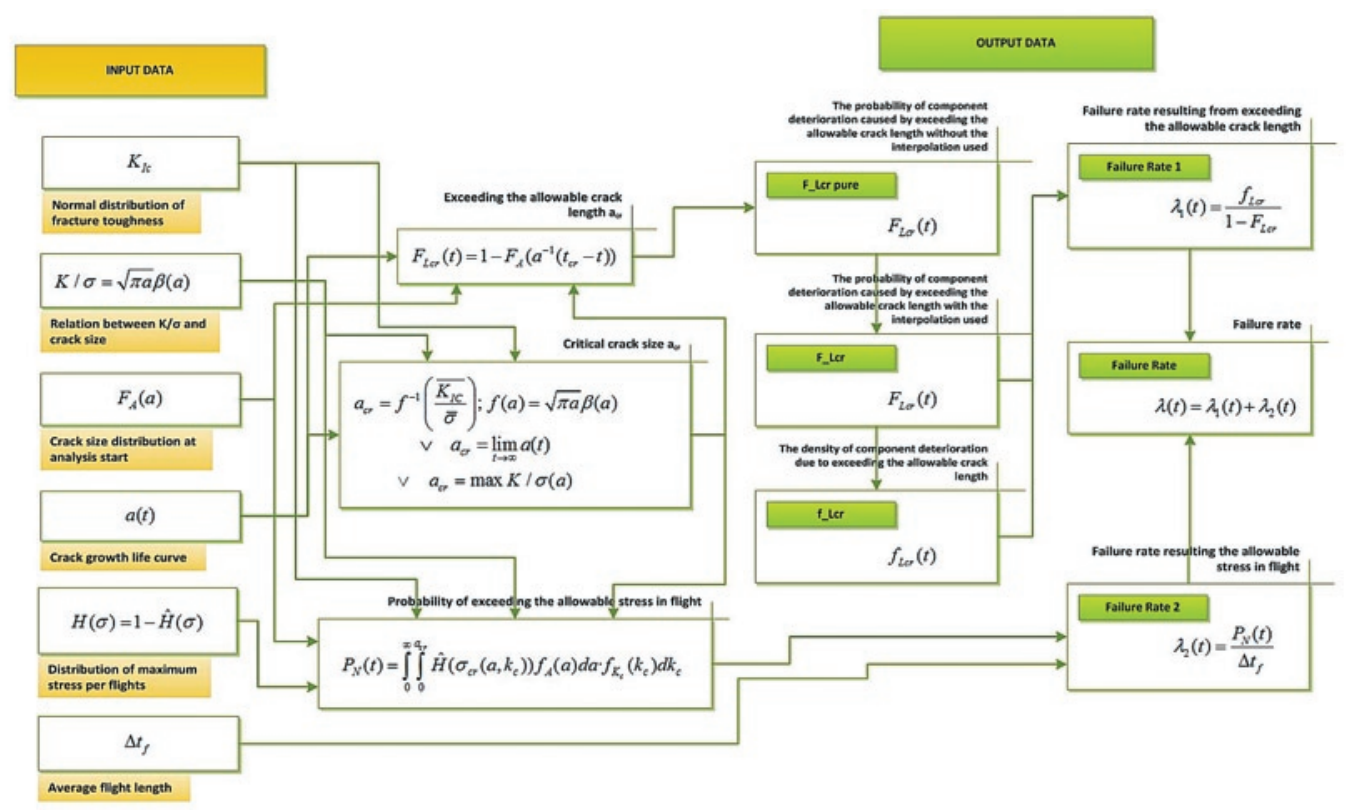

Fig. 1. Graphical representation of the applied mathematical model 


$$
\lambda_{2}(t)=\frac{P O F(t)}{\bar{t}}
$$

where $\bar{t}$ is the average flight length.

A method of assessing the reliability of the aircraft airframe has been developed for the purpose of reliability analysis of PZL-130 Orlik TC-II aircraft. It was necessary also to create the innovative Aircraft Structural Reliability Assessment (AStRAss) software, which implements the method developed by author, in order to calculate the reliability of the selected control points in aircraft airframe under real operating conditions.

Numerical implementation of failure rate for the place in the aircraft structure, calculated on the basis of equation (4), was completed according to the scheme shown in Fig. 1.

Failure rate depending on exceeding the allowable crack length $a_{c r}$ is calculated on the basis of initial crack size distribution function $F_{A}(a)$ and the crack growth function $a(t)$.

The critical crack length is calculated according to formula (6) using linear interpolation. In case, when the search value exceeds the values from the input array $K / \sigma$, as a critical values one assumes the smaller value of the crack length from an array of function $a(t)$ or $K / \sigma$.

For each value of the crack length $a_{i}$ from the array of cumulative distribution function of the initial crack size, the time $t_{i}$ in which this crack length will be obtained and time to failure $t_{f i}$ are assigned, as shown graphically in Figure 2.

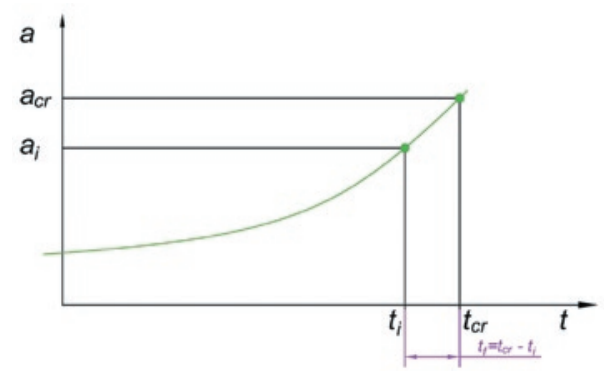

Fig. 2. The crack growth function a(t)

Probability function of component deterioration $F_{L c r}(t)$ is created from the array of time to failure $t_{f}$ and an array of $1-F_{A}$, as shown in Figure 3. Polynomial interpolation of the probability function of component deterioration in selected time points, which is given as an input parameter, is based on finite differences. The probability density function $f_{L C r}$ is calculated using numerical differentiation.

It is possible that when using polynomial interpolation or numerical integration, the probability function of component deterioration $F_{L c r}(t)$ or the probability density function $f_{L c r}$ will locally have a value lower than zero. In this case, the minimum allowed by the decimal type variable value (amounting $10^{-28}$ ) is generated. In the case where there is a correct value for the previous time instant, this value increased by $10^{-28}$ is assumed. An appropriate message in the text message field of AStRAss software is then displayed.

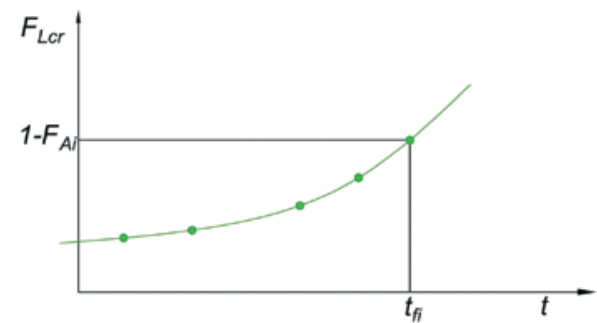

Rys. 3. Function graph of the probability of component deterioration $F_{L c r}(t)$
Failure rate caused by exceeding the maximum stresses in flight shall be calculated using equation (10). The probability that the stress value will cause damage during flight at the time $t$ for failures of the crack length less than $a_{c r}$, described by equation (9), can be calculated by:

$$
P_{N}(t)=\int_{0}^{a_{c r}} f_{A}(a) \int_{0}^{\infty} f_{K_{c}}\left(k_{c}\right) \cdot \hat{H}\left(\sigma_{c r}\left(a, k_{c}\right)\right) d k_{c} d a
$$

The above equation can be represented as:

$$
P_{N}(t)=\int_{0}^{a_{c r}} f_{A}(a) P_{A}(a) d a
$$

where: $\quad P_{A}(a)$ is the probability of failure for a specified crack length, expressed by:

$$
P_{A}(a)=\int_{0}^{\infty} f_{K_{c}}\left(k_{c}\right) \cdot \hat{H}\left(\sigma_{c r}\left(a, k_{c}\right)\right) d k_{c}
$$

Equation (12) is an analytical formula to determine the probability of failure in flight for a particular stress value. Numerical implementation strictly from formula (12) is susceptible to inaccuracy, because probability density function $f_{A}(a)$ of the crack length at the time $t$ is derived from the tabular cumulative distribution function of the crack length $F_{A}(a)$ and not from the clearly defined mathematical formula. In order to minimize numerical errors change of variables has been applied. If the variable $u$ is a uniform random variable from the interval $(0,1)$, then the variable $a_{1}=F_{A}^{-1}(u)$ has the cumulative distribution function $F_{A}\left(a_{1}\right)[3,13]$. Equation (12) can therefore be expressed as:

$$
P_{N}(t)=\int_{0}^{u_{c r}(t)} P_{A}\left(F_{A}^{-1}(u)\right) d u
$$

where: $u_{c r}(t)=F_{A}\left(a_{c r}\right)$ at time $t$,

$F_{A}^{-1}(u)$ is the inverse of cumulative distribution function of crack length at time $t$.

Equation (13) was calculated on the basis of definition by applying integration of trapezium method. Interval $(0,+\infty)$ was limited to the $(\mu-4 \cdot \sigma, \mu+4 \cdot \sigma)$, where $\mu$ is the mean value and $\sigma$ is a standard deviation, which covers more than $99.7 \%$ of the entire range.

\section{Reliability analysis - input data}

Reliability analysis has been performed for the area situated on the fuselage, for a possible failure in the area of the upper left side canopy longeron at the middle lock cut out. During the full-scale fatigue test a cracked left upper longeron was observed in this place. The defect was classified as PTC (Plate Through Thickness Crack) [5] (shown in Fig. 4). The finite element method (FEM) model study area is shown in Fig. 5.

The parameter values determining the normal distribution of constant $K_{I c}$ which define the fracture toughness for flat samples across the grain (L-T reference directions) made of 2024-T351 alloy, which correspond to the damage at control point, have been adopted on the basis of the literature [19]:

$$
\text { - mean value } 36,7 \mathrm{MPa} \sqrt{\mathrm{m}} \text {, }
$$



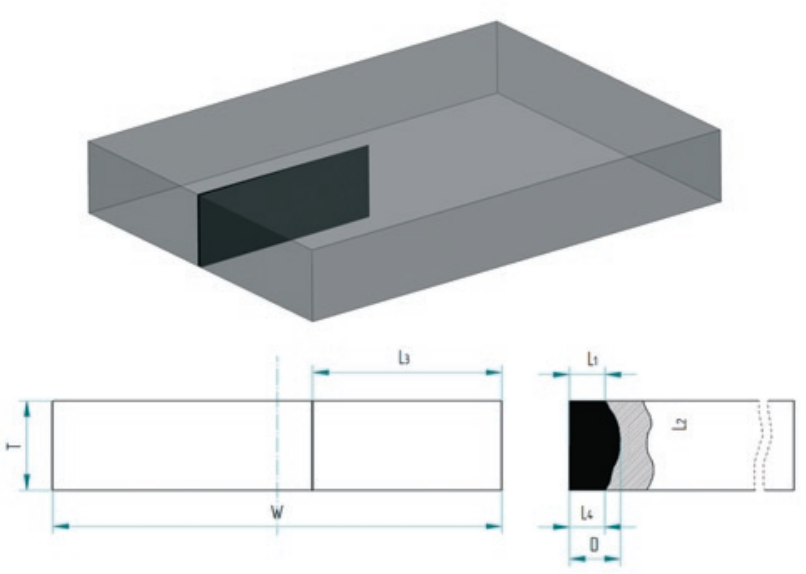

Fig. 4. PTC (Plate Through Thickness Crack) type damage on the graphic scheme

where: $T-$ component thickness,

$W \quad$ - component width,

$D \quad$ - maximum crack length,

$L_{1} \quad$ - crack length from the upper edge,

$L_{2} \quad$ - crack length from the lower edge,

$L_{3} \quad$ - length of not cracked material.

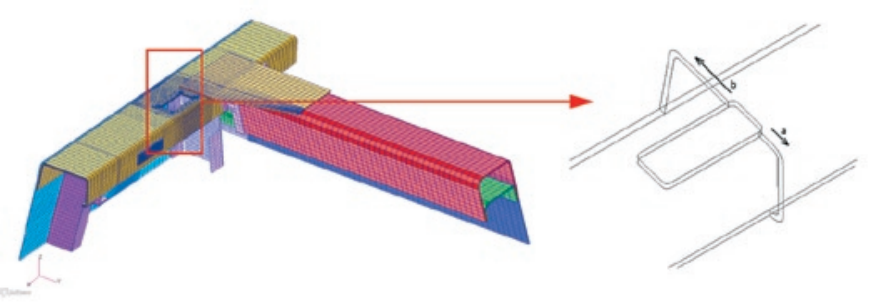

Fig. 5. FEM model of the probable crack location [15, 16]

- standard deviation 4,29 $M P a \sqrt{m}$.

FEM analysis was performed with the use of MSC Software [15]. Based on the FEM analysis results the following relation between stress intensity factor, stress $(K / \sigma)$, and crack size $a$ has been established:

Calculations of failure propagation in AFGRWO programme might be performed only for models not containing holes. Due to this fact the crack was divided into two sections, as shown in Figure 5.

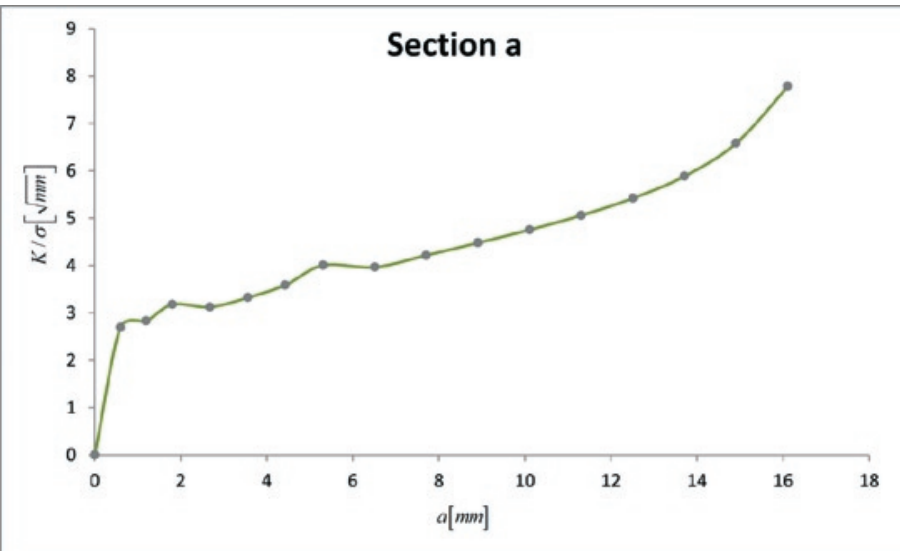

Based on flight data records covering the period from the beginning of operation of Orlik aircraft in the Polish Air Force, the average length of the flight was determined to be 43 minutes.

By means of AFGROW software the curve shape was obtained. It is presented in black in Fig. 7. Green colour indicates an adequate fit to the equation (11). Red curves indicate extrapolation with the use of exponential function:

$$
a(t)=a_{0} e^{b t}
$$

In calculations a simple through crack propagating from one side of the model was used. The relation between $\beta(a)$ and crack length as well as the load spectrum based on strain gauge measurements were used. Material properties for 2024-T351 aluminum alloy such as Young's modulus $(E)$ and $K_{I C}$ were established based on tests carried out in the laboratory [19]. Model data used in calculations are presented in Table 1.

Table 1. Data used in crack propagation calculations [15]

\begin{tabular}{||l|l|l||}
\hline \multicolumn{1}{|c|}{ Parameter } & \multicolumn{1}{c|}{ Section a } & \multicolumn{1}{c|}{ Section b } \\
\hline Element length & $0.04857[\mathrm{~m}]$ & $0.06283[\mathrm{~m}]$ \\
\hline Element thickness & $0.0025[\mathrm{~m}]$ & $0.0025[\mathrm{~m}]$ \\
\hline Initial crack length & $0.00143[\mathrm{~m}]$ & $0.00143[\mathrm{~m}]$ \\
\hline $\mathrm{K}_{\mathrm{IC}}$ & $36.75[\mathrm{MPa} \sqrt{\mathrm{m}}]$ & $36.75[\mathrm{MPa} \sqrt{\mathrm{m}}]$ \\
\hline $\mathrm{E}$ & $72000[\mathrm{MPa}]$ & $72000[\mathrm{MPa}]$ \\
\hline Stress Multiplication Factor & $0.072[-]$ & $0.072[-]$ \\
\hline
\end{tabular}

The distribution of maximum stress peak in a flight is modelled in terms of a Gumbel distribution of extreme values and is based on flight research results:

$$
H(\sigma)=\exp \left[-\exp \left(-\frac{\sigma-B}{A}\right)\right]
$$

where: $\sigma$ - stress,

A - Gumbel distribution parameter determining the slope of the cumulative distribution function,

$B \quad$ - Gumbel distribution parameter determining the 37th percentile of maximum stress on flights.

To achieve A and B parameters of Gumbel distribution the correlation between maximum vertical load values $n_{z}$ and stresses occurring on strain gauge using 285 development flights for this purpose. During these flights one utilizes KAM 500 data recorder [11, 17]. The next step of the calculation was to obtain a transfer function relat-

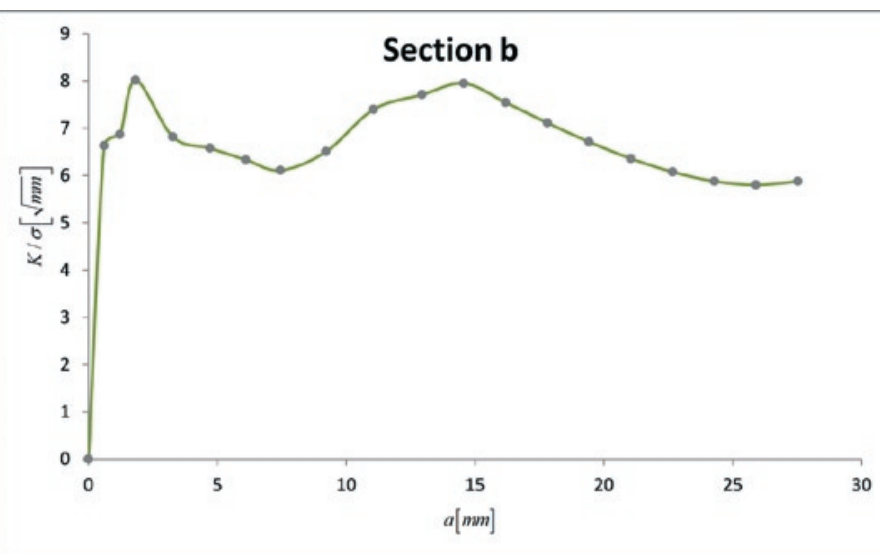

Fig. 6. Dependence K/ $\sigma$ from crack length 

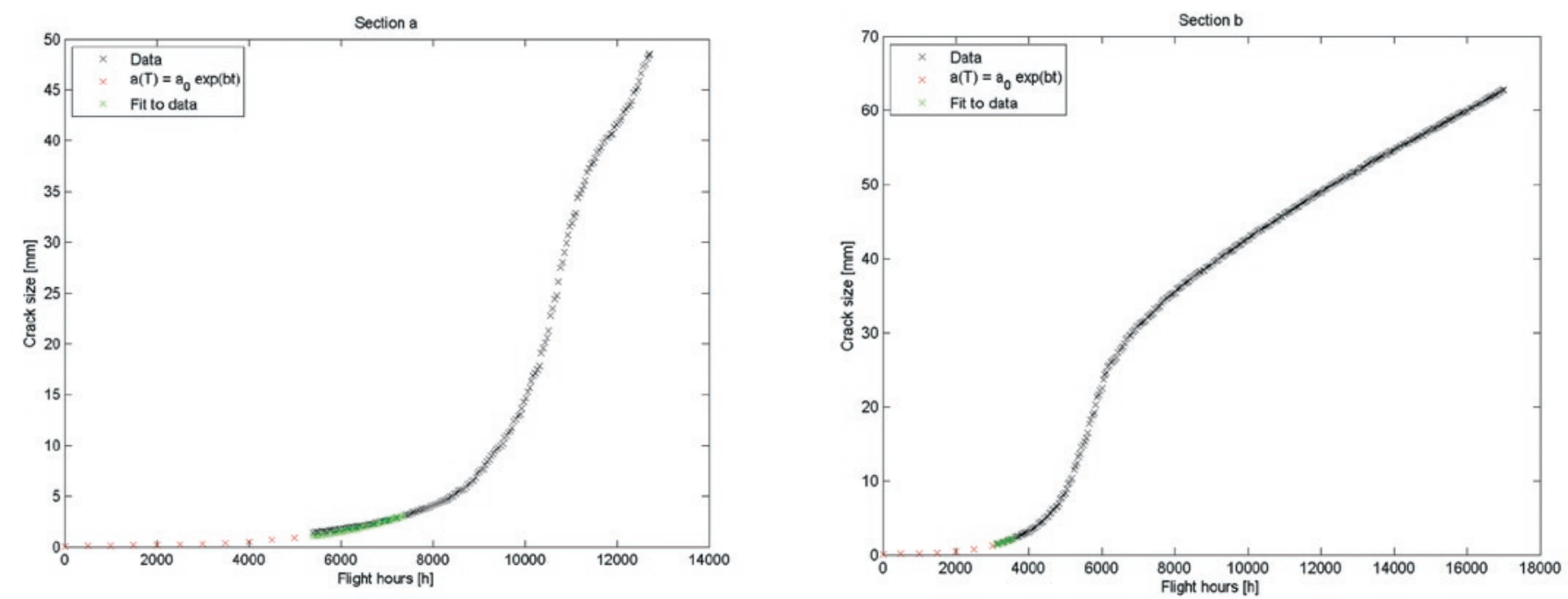

Fig. 7. Relation of crack length from flight time
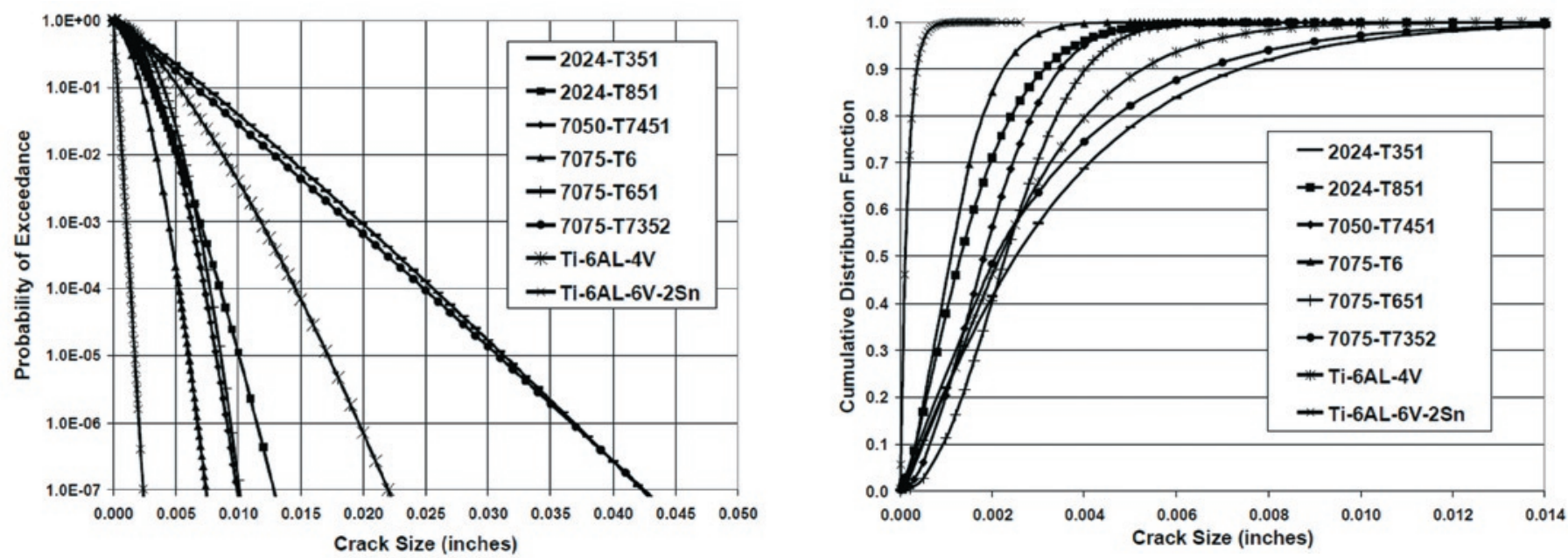

Fig. 8. Inverse of cumulative distribution function and cumulative distribution function of initial flow sizes (EIFS) [5]

ing vertical load factor $n_{z}$ and stress. The calculations were conducted with the application of the algorithm of linear approximation of the method of the least squares or by way of using the non-linear Levenberg-Marquardt regression algorithm. Stresses resulting from the global model from FEM calculations for $n_{z}=1$ in the region of interest were extracted. For calculations the coefficients of transfer function and maximum exceedance of vertical load factor $n_{z}$ were obtained from on-board flight recorders mounted on PZL-Orlik TC-I and TCII aircrafts from the beginning of operation until 2010 were used. At that time more than 40000 flights were performed. Stress values were estimated to the Gumbel distribution with the following coefficients:

$$
\begin{aligned}
& -\mathrm{A}=8.6[\mathrm{MPa}], \\
& -\mathrm{B}=71.9[\mathrm{MPa}],
\end{aligned}
$$

using a fitting for flight, in which vertical load factor $n_{z}>4.6$.

The initial crack size distribution was adopted pursuant to the article [5] (fig. 8). Data from literature were estimated using a Weibull distribution:

$$
F_{A}(a)=1-e^{-(a / \lambda)^{k}}
$$

where: $\lambda$ - scale parameter,

$$
k \quad \text { - shape parameter. }
$$

The initial crack size distribution resembles the Weibull distribution function, which was justified by Yang and Manning [21, 28]. Following parameters were assumed for calculations: $\lambda=0.0891$ $\mathrm{mm}, k=1.1204$.

\section{Result}

For the failure section $b$, it is assumed that the beginning of crack propagation will be a time instant in which a section is damaged. For military aircrafts it is recommended to determine the event as unlikely

Table 2. Probability levels [14]

\begin{tabular}{||c|c|c|c|}
\hline Description & Level & Individual Aircraft & Fleet \\
\hline \hline Remote & D & $\begin{array}{c}\text { Unlikely, but possible to occur } \\
\text { in the life of an item during } \\
\text { service life of the aircraft. } \\
\text { Probability of occurrence less } \\
\text { than } 10^{-3} \text { but greater than or } \\
\text { equal to } 10^{-6}\end{array}$ & $\begin{array}{c}\text { Unlikely but } \\
\text { can reason- } \\
\text { ably be } \\
\text { expected to } \\
\text { occur }\end{array}$ \\
\hline Improbable & E & $\begin{array}{c}\text { So unlikely, it can be assumed } \\
\text { that the occurrence will not } \\
\text { be experienced in the life of } \\
\text { an item. Probability of occur- } \\
\text { rence less than } 10^{-6}\end{array}$ & $\begin{array}{c}\text { Unlikely to } \\
\text { occur, but pos- } \\
\text { sible }\end{array}$ \\
\hline
\end{tabular}




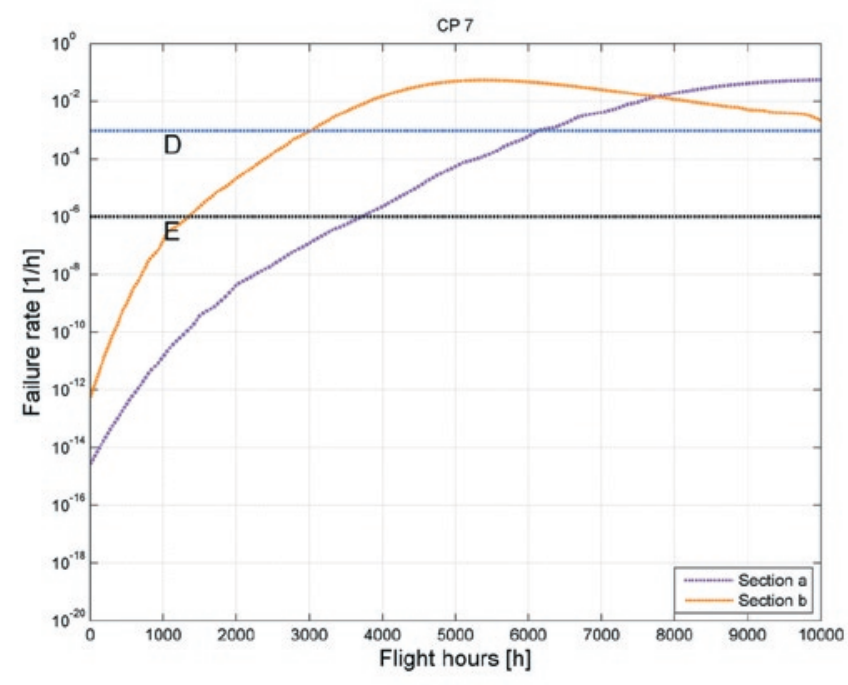

Fig. 9. Failure rate
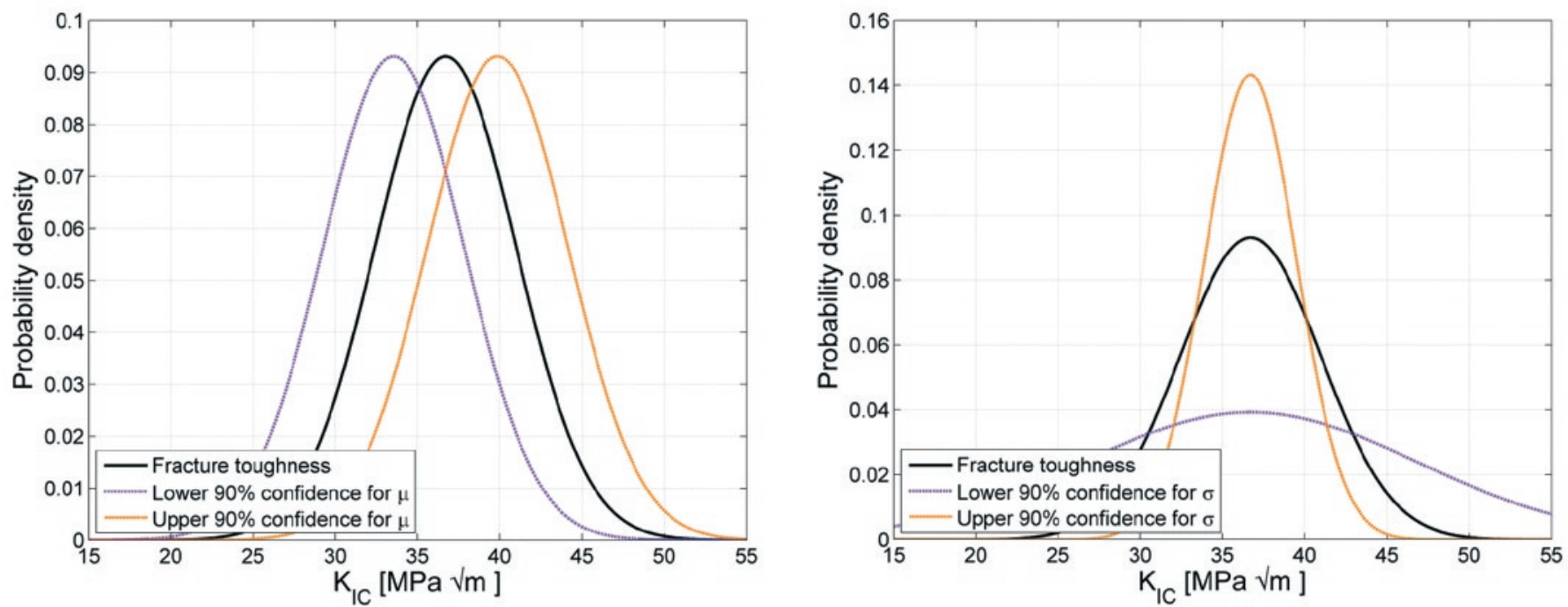

Fig. 10. Fracture toughness distribution within the confidence interval for mean value $\mu$ and standard deviation $\sigma$
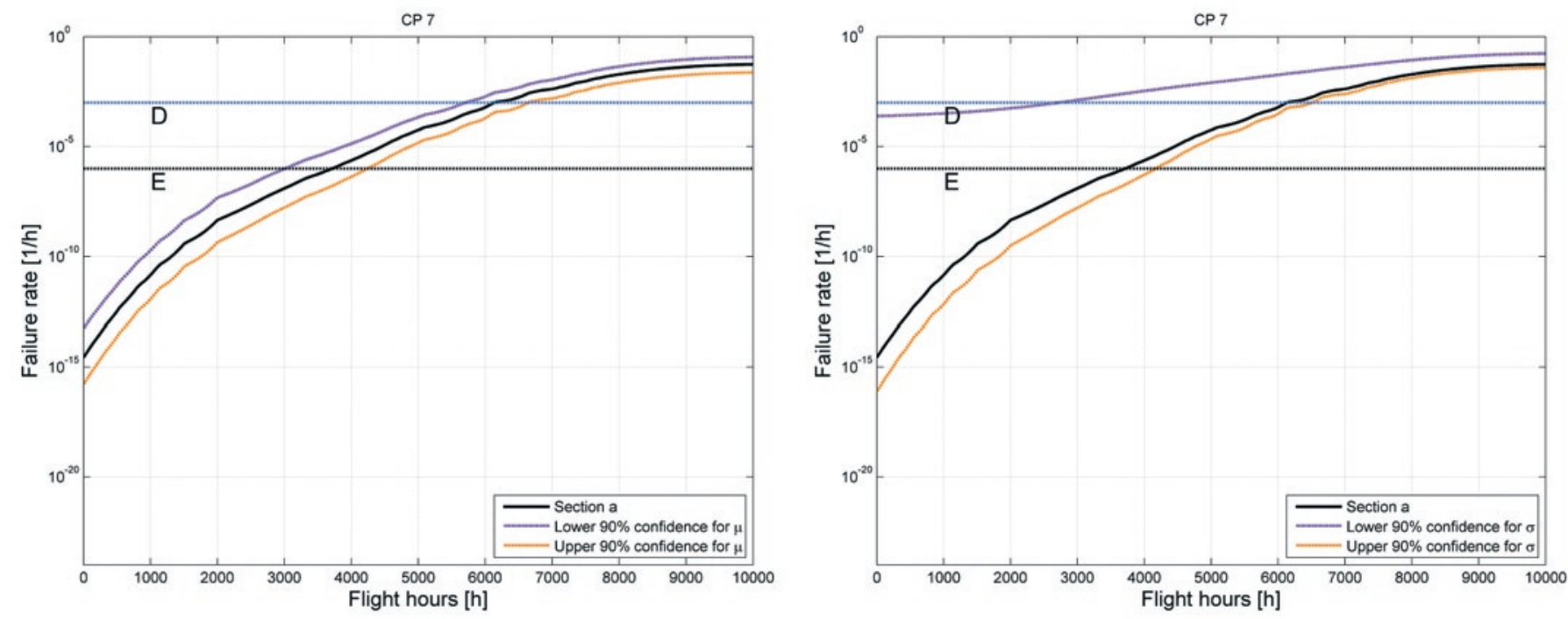

Fig. 11. Failure rate for the section a of the control point for different values of the mean value $\mu$ and standard deviation $\sigma$ of the normal distribution of fracture toughness $K_{I c}$ 
Table 3. Weibull parameters distribution of initial crack size

\begin{tabular}{|c|c|c||}
\hline & [mm] & [in.] \\
\hline The scale parameter $\lambda$ & 0.0891 & 0.0035072 \\
$110 \% \cdot \lambda$ & 0.0980 & 0.0038579 \\
$90 \% \cdot \lambda$ & 0.0802 & 0.0031565 \\
\hline & {$[-]$} & \\
\hline The shape parameter $k$ & 1.1204 & \\
$110 \% \cdot k$ & 1.2324 & \\
$90 \% \cdot k$ & 1.0084 & \\
\hline
\end{tabular}

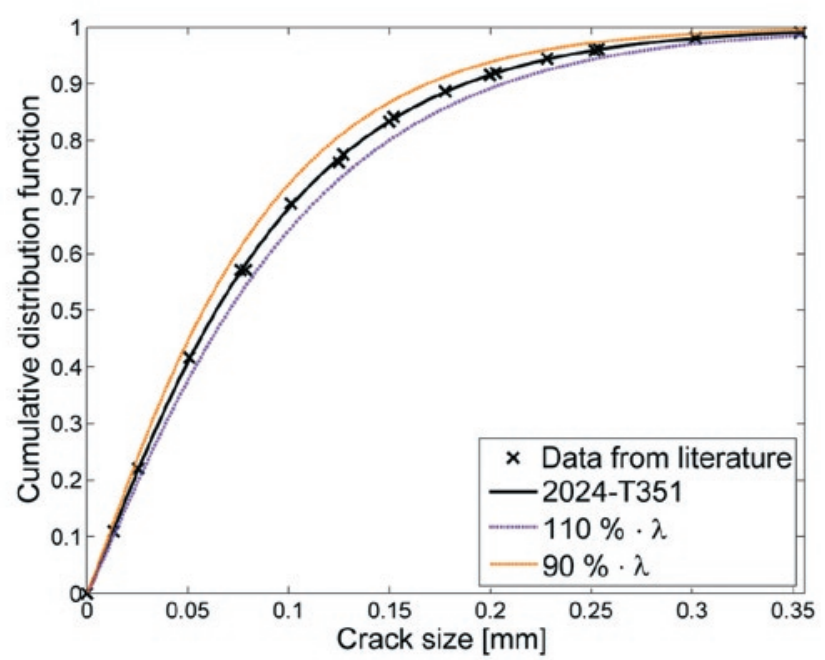

$\sigma$ of the established normal distribution $K_{I c}$. Sensitivity on fracture toughness variations was performed by changing the mean value $\mu$ and standard deviation $\sigma$ to reflect potential uncertainty of parameters, which are often described on the basis of samples from different manufacturing batches of the material.

The parameter values $K_{I c}$ for flat samples across the grain (L-T reference directions), which correspond to the damage in control point 7, for 2024-T351 alloy, were adopted pursuant to the literature [19] and have been based on five samples.

Ninety-percent confidence interval for the mean value $\mu$ and standard deviation $\sigma$ for five samples was calculated applying the maximum likelihood method [20] and it is as follows:

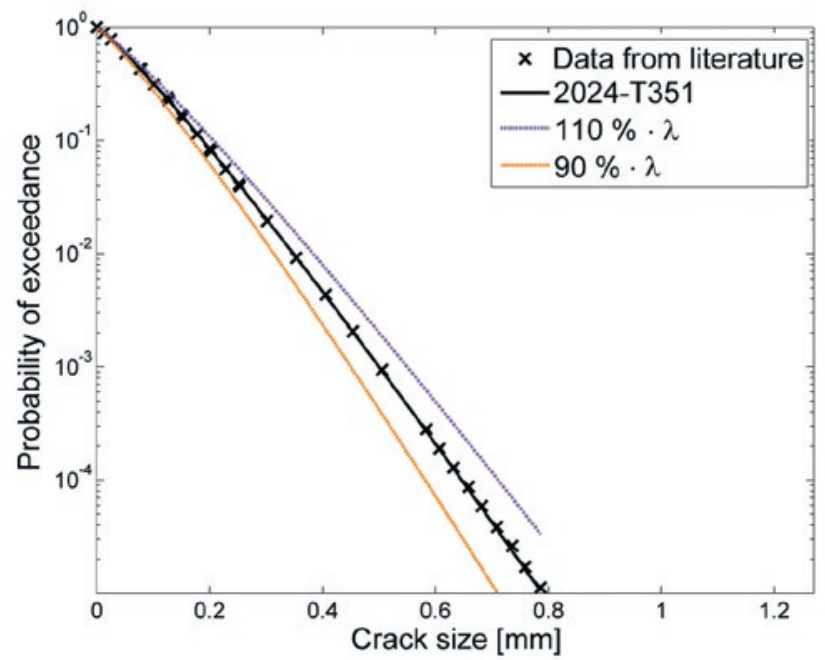

Fig. 12. Cumulative distribution function and inverse of cumulative distribution function of equivalent distribution of initial flaw sizes (EIFS) when the scale parameter $\lambda$ was modified
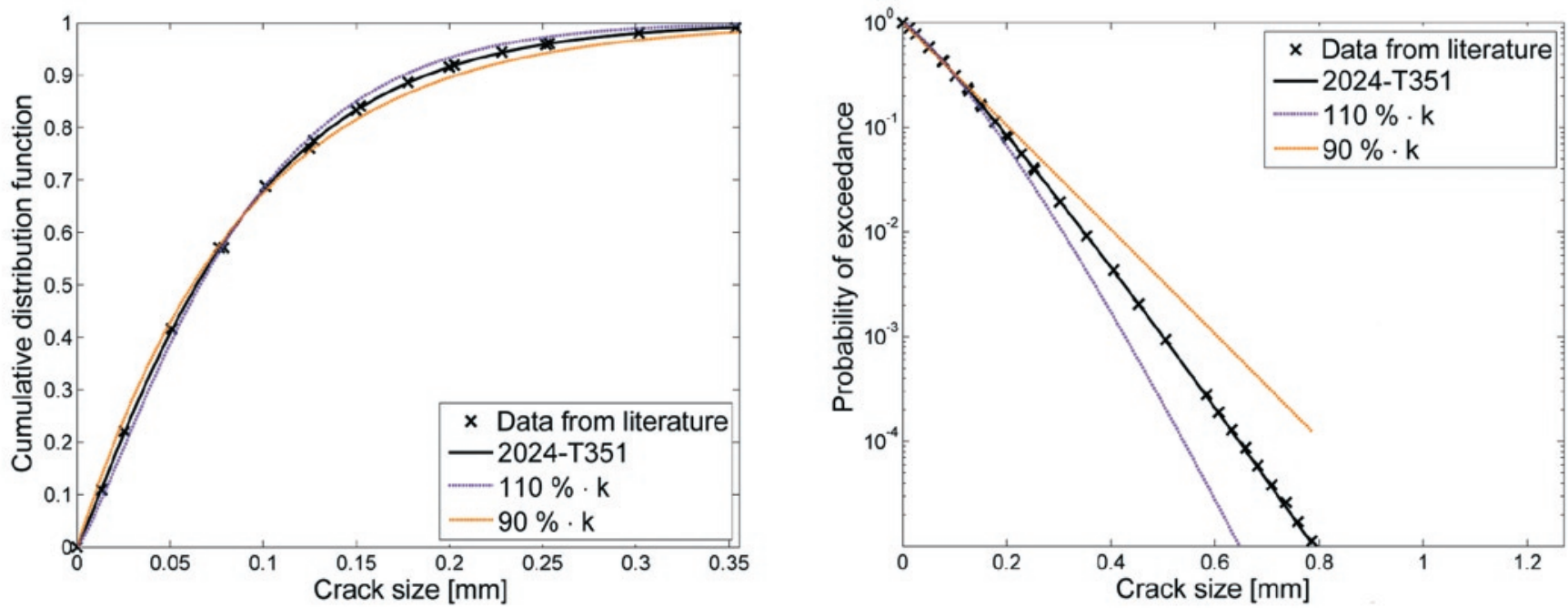

Fig. 13. Cumulative distribution function and inverse of cumulative distribution function of equivalent distribution of initial flaw sizes (EIFS) when the shape parameter $k$ was modified

samples across the grain (L-T reference directions), made of 2024T351 alloy, and the initial crack size distribution.

Sensitivity analysis of calculation results of structure failure probability of PZL-130 Orlik TC-II airframe on changes of input data parameters allowed to assess the impact of the parameters (which were assumed on the basis of literature) on final results.

Analysis of sensitivity to the change of fracture toughness $K_{I c}$

Fracture toughness, for the specified control point of the airframe, is defined by determining the mean value $\mu$ and standard deviation
- mean value $(33.54 ; 39.86) M P a \sqrt{m}$,

- standard deviation $(10.17 ; 2.78) \operatorname{MPa} \sqrt{m}$.

Figure 10 shows the differences in fracture toughness distribution when the mean value $\mu$ and standard deviation $\sigma$ are in extreme points of these confidence intervals.

The results of calculations are illustrated in Figure 11.Based on the failure rate curves (Fig. 11) it can be inferred that both the change 

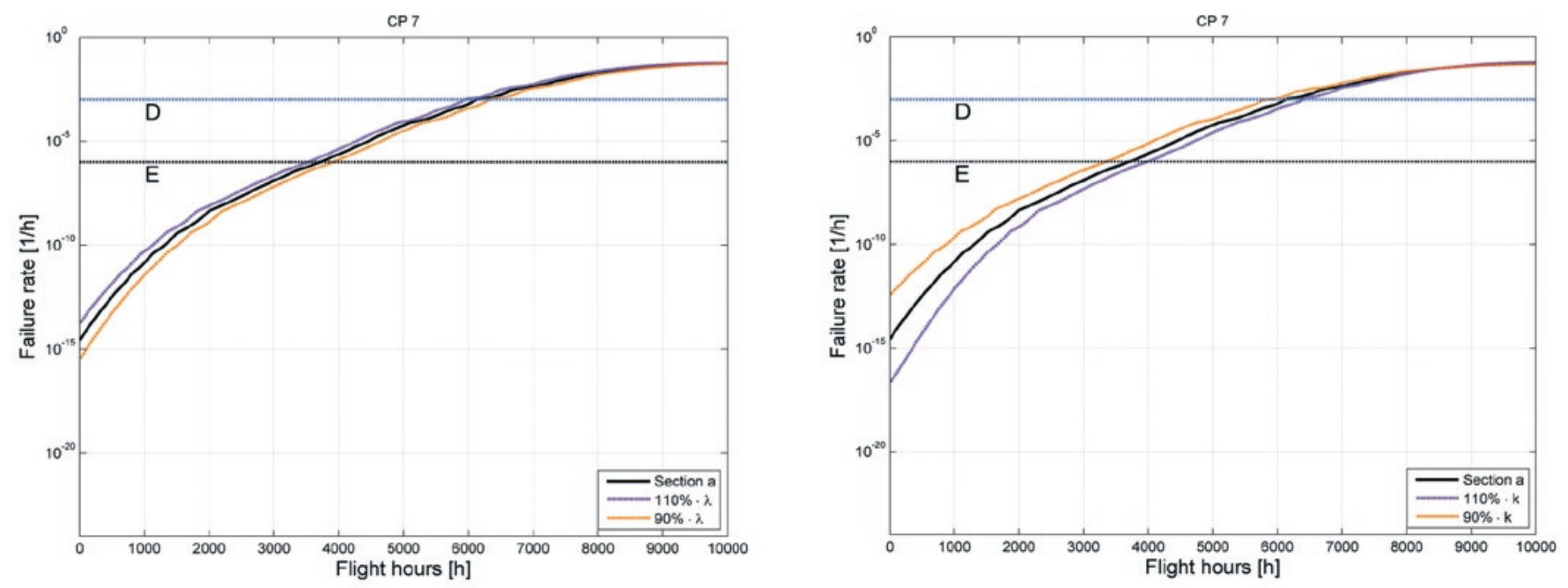

Fig. 14. Failure rate for the section a of the control point for different parameter values of scale $\lambda$ and shape parameter $k$ of Weibull distribution of initial crack size

in the parameter of mean value $\mu$ or standard deviation $\sigma$ will significantly affect the final results. The change of $10 \%$ of the confidence interval of standard deviation $\sigma$, as compared to the 10-percent change of the confidence interval of the mean value, in the final result will cause more intense disturbance. The initial, significant divergence of results when changing the standard deviation $\sigma$ fades with time, as has been well shown in Fig. 11.

Analysis of sensitivity to changes of initial crack size distribution

The sensitivity of failure rate to the initial crack size distribution was investigated by the change of parameters in two different ways:

- the scale parameter $\lambda$ of the baseline Weibull distribution was arbitrarily increased and decreased 10 percent with a shape parameter $k$ at baseline,

- the shape parameter $k$ of the baseline Weibull distribution was arbitrarily increased 10 and decreased percent with a scale parameter $\lambda$ at baseline.

Parameter values of Weibull distribution for sensitivity analysis were collected and presented in Table 3. Figures 12 and 13 illustrate the initial crack size distributions used for calculations of sensitivity analysis. The calculation results are shown in Figure 14.

Based on the graphs of failure rate (Fig. 14), it can be inferred that both the scale parameter $\lambda$ and the shape parameter $k$ does not affect the final results to great extent. In the area, which is the most significant in terms of reliability, where the instantaneous failure rate is greater than $10^{-3}$, the results slightly differ. The change by $10 \%$ of shape parameter $k$, as compared to the $10 \%$ change of scale parameter $\lambda$, will cause more intensive change in the final result. Since the results deviations are minor, therefore, it can be concluded that the reliability analysis of structure is not significantly susceptible to the initial crack size distribution.

\section{Conclusions}

The obtained simulation results indicate that a crack on the fuselage, on the upper left side canopy longeron near the middle lock cut out for 6000 hours of service life can be described as unlikely (remote), since the probability of fracture, provided that the damage did not occur previously is less than $10^{-3}$ during the aircraft operation time. The shape of the obtained curve for section a shown in Fig. 9 is due to a moderate increase of the crack propagation curve in the initial periods of aircraft service life and a relatively low stress value at the considered control point with respect to the curve describing the relation of stress intensity factor to stresses depending on crack length. Assuming that the inner canopy section will start to propagate at a time when the previous section, located outside the canopy fails, the probability of failure in the next hour of flight significantly increases. The most important factor influencing the failure rate of section $b$ is the crack propagation rate. This damage can be described as unlikely (remote) for 3000 hours of aircraft service life, since the probability of occurrence is less than $10^{-3}$, but greater than $10^{-6}$.

For section $\mathrm{b}$ a graphical comparison of relation between stress intensity factor, stresses $(K / \sigma)$, and crack size $a$ (Fig. 6) together with chart portraying failure rate (Fig. 9) demonstrated a strong influence of geometry correction factor $(\beta(a))$ on reliability. The fact that $(K / \sigma)$ curve for crack length of $\sim 40 \mathrm{~mm}$ (Fig. $6 b$ ) is not monotonic, suggests the decrease of the failure rate decrease of about 5000 flight hours.

The presented analyses have confirmed that it is possible and also advisable to determine the reliability at the points of the selected critical airframe locations. This kind of approach, while monitoring failures, allows to optimise the process of flight approval, while ensuring the safety of an aircraft during operation.

In addition, it was possible to specify the most important input parameters that have the greatest impact on the final assessment of the reliability at the checkpoints of airframe critical locations. The present research suggests that in the case of airframe components, essential for reliability are the parameters that define the crack propagation rate and structural determinants expressed by the dimensionless geometry correction factor, which specifies the state of stress in the crack tip and takes into account the shape of the tested element, independent of the applied load.

The methodology with implementation to evaluate the reliability of the selected control points of the supporting structure in the developed software has been designed in such a way, so as to allow implementation of any type of aircraft. Reliability analysis enables to determine the changes over time of the fatigue failure probability in the aircraft structure. The results of this analysis provide the basis for determining safe intervals between successive inspections of aircraft structures.

\section{References}

1. Babish C. Application of risk \& reliability analysis for fatigue cracking in F-16 aircraft structure. Technical report, 2010 F-16 ASIP.

2. Bedford T. Cooke R. Probabilistic Risk Analysis Foundations and Methods. Cambridge: Cambridge University Pressn, 2001, https://doi. 
org/10.1017/CBO9780511813597.

3. Devroye L. Non- Uniform Random Variate Generation. Springer-Verlag New York Berlin Heidelberg Tokyo, Harrisonburg, Virginia, United States of America, 1986, https://doi.org/10.1007/978-1-4613-8643-8.

4. Dixon B. Molent L. Ex-Service F/A-18 Centre Barrel Fatigue Flaw Identification Test Plan. Melbourne: DSTO Platforms Sciences Laboratory, 2003.

5. Gallagher J. Babish C. Malas J. Damage Tolerant Risk Analysis Techniques for Evaluating the Structural Integrity of Aircraft Structures. 11th International Conference on Fracture 2005; 1: 71-76.

6. Hinz M. Luecker A. Knuebel G. Bracke S. Reliability Analysis of Organic Fibres using Limited Data. 2015 61ST Annual Reliability And Maintainability Symposium (RAMS 2015), 2015.

7. Hinz M. Hienzsch F. Bracke S. Analysis of Simulated and Recorded Data of Car Fleets Based on Machine Learning Algorithms. 13th International Conference on Probabilistic Safety Assessment and Management (PSAM 13) in prep. 2016.

8. Jankowski K. Reymer P. Simulating crack propagation of the selected PZL-130 ORLIK TC-II aircraft structural component. Fatigue of Aircraft Structures 2014; 1(6): 119-127, https://doi.org/10.1515/fas-2014-0013.

9. Koucky M. Valis D. Reliability of sequential systems with a restricted number of renewals. Proceedings and Monographs in Engineering, Water and Earth Sciences 2007; 1845-1849.

10. Leski A. An Algorithm of Selecting a Representative Load Sequence for a Trainer. 2nd International Conference on Engineering Optimization 2010; CD: $1-8$.

11. Leski A. Reymer P. Kurdelski M. Development of Load Spectrum for Full Scale Fatigue Test of a Trainer Aircraft. ICAF 2011 Structural Integrity: Influence of Efficiency and Green Imperatives 2011: 573-584.

12. Liao M. Bombardier Y. Renaud G. Bellinger N. Cheung T. Development of advanced risk assessment methodologies for aircraft structures containing MSD/MED. ICAF 2009 Bridging the Gap between Theory and Operational Practice 2009: 811-837.

13. Miedlar P. Berens A. Hovey P. Boehnlein T. Loomis J. PRoF v3 PRobability Of Fracture Aging Aircraft Risk Analysis Update. Dayton: University of Dayton Research Institute, 2005.

14. MIL-STD-882E, Department of Defense, Standard Practice For System Safety 2012.

15. Podskarbi S. Leski A. Reymer P. Jankowski K. Kurdelski M. Stefaniuk M. Obliczenia stanu naprężenia oraz obliczenia szybkości wzrostu pęknięć dla CP z wykorzystaniem rzeczywistych widm obciążeń eksploatacyjnych. Sprawozdanie nr SP-58/31/2014. Warsaw: Air Force Institute of Technology, 2014.

16. Reymer P. Jankowski K. Kłysz S. Lisiecki J. Leski A. Crack propagation of the selected PZL-130 Orlik TC-II aircraft structural component based on laboratory test results. Proceedings of the Fourth Asian Conference on Mechanics of Functional Materials and Structures 2014, $181-184$.

17. Reymer P. Leski A. Flight Loads Acquisition for PZL-130 ORLIK TCII Full Scale Fatigue Test. Fatigue of Aircraft Structures 2011; 3: 78-85, https://doi.org/10.2478/v10164-010-0041-7.

18. Rudd J. Yang J. Manning S. Garver W. Durability Design Requirements and Analysis for Metallic Airframes. Design of Fatigue and Fracture Resistant Structures, ASTM STP 761, American Society for Testing and Materials 1982; 133-151.

19. Skinn D. A. Gallagher J. P. Berens A. P. Huber P. D. Smith J. Damage Tolerant Design Handbook. Wright Laboratory, Wright Patterson AFB, Ohio 45433-7734, 1994.

20. Taboga M. Lectures on Probability Theory and Mathematical Statistics - 2nd Edition, second ed. CreateSpace Independent Publishing Platform, 2012.

21. Tomaszek H. Jasztal M. Zieja M. Application of the Paris formula with $m=2$ and the variable load spectrum to a simplified method for evaluation of reliability and fatigue life demonstrated by aircraft components. Eksploatacja i Niezawodnosc - Maintenance and Reliability 2013; 4: 297-303.

22. Tomaszek H. Zieja M. Wazny M. A method for reliability assessment of structural components of aircraft and sea-going ships with taking into account a given failure generation model. Polish Maritime Research 2016; 2(23): 83-90.

23. Valis D. Koucky M. Zak L. On approaches for non-direct determination of system deterioration. Eksploatacja i Niezawodnosc - Maintenance and Reliability 2012; 1: 33-41.

24. Valis D. Vintr Z. Dependability of mechatronics systems in military vehicle design. Proceedings and Monographs in Engineering, Water and Earth Sciences 2006; 1703-1707.

25. Valis D. Vintr Z. Koucky, M. Contribution to highly reliable items' reliability assessment. Reliability, Risk and Safety: Theory and Applications 2010; 1-3: 1321-1326.

26. White P. Molent L. Barter S. Interpreting fatigue test results using a probabilistic fracture approach. International Journal of Fatigue 2005; 27: 752-767, https://doi.org/10.1016/j.ijfatigue.2005.01.006.

27. Zieja M, Ważny M, Stępień S. Distribution determination of time of exceeding permissible condition as used to determine lifetimes of selected aeronautical devices/systems. Eksploatacja i Niezawodnosc - Maintenance and Reliability 2016; 18 (1): 57-64, http://dx.doi.org/10.17531/ ein.2016.1.8. Zieja M. Wazny M. Stepien, S. Distribution determination of time of exceeding permissible condition as used to determine lifetimes of selected aeronautical devices/systems. Eksploatacja i Niezawodnosc - Maintenance and Reliability 2016; 1(18): 57-64.

28. Zurek J. Tomaszek H. Zieja M. Analysis of structural component's lifetime distribution considered from the aspect of the wearing with the characteristic function applied. Safety, Reliability and Risk Analysis: Beyond the Horizon 2014; 2597-2602.

\section{Marta WOCH}

Division of Fundamentals of Machine Design

Warsaw University of Technology

ul. Nowowiejska 24, 00-665 Warsaw, Poland

E-mail:marta.woch@itwl.pl 